\title{
The Consequences of Spatial Inequality for Adolescent Residential Mobility
}

\author{
Matt Vogel ${ }^{1,2, *}$ and Merle Zwiers ${ }^{2}$ \\ 1 Department of Criminology and Criminal Justice, University of Missouri-St. Louis, \\ St. Louis, MO 63121, USA \\ 2 OTB Research Institute for the Built Environment, Delft University of Technology, Delft 2628, \\ The Netherlands; M.D.Zwiers@tudelft.nl \\ * Correspondence: vogelma@umsl.edu; Tel.: +314-516-5042
}

Received: 10 July 2018; Accepted: 13 September 2018; Published: 15 September 2018

check for updates

\begin{abstract}
A large body of literature suggests that neighborhood socioeconomic disadvantage is positively associated with out-mobility. However, prior research has been limited by (1) the inability to account for endogenous factors that both funnel families into deprived neighborhoods and increase their likelihood of moving out, and (2) the failure to consider how the spatial distribution of socioeconomic deprivation in the broader community conditions the effect of local deprivation on mobility. This paper attends to this gap in the literature by examining how changes in socioeconomic disadvantage between sending and receiving neighborhoods and the spatial patterning of deprivation in the areas surrounding destination neighborhoods influence future mobility among a representative sample of American adolescents. We employ a modeling strategy that allows us to examine the unique and separable effects of local and extralocal neighborhood disadvantage while simultaneously holding constant time-invariant factors that place some youth at a greater likelihood of experiencing a residential move. We find that moves to more impoverished neighborhoods decrease the likelihood of subsequent mobility and that this effect is most pronounced among respondents who move to neighborhoods surrounded by other similarly deprived neighborhoods. In this sense, geographical pockets of disadvantage strengthen the mobility-hampering effect of neighborhood deprivation on future mobility.
\end{abstract}

Keywords: residential mobility; neighborhood disadvantage; extralocal disadvantage; neighborhood selection

\section{Introduction}

Residential mobility is often viewed as a disruptive process in the lives of children and adolescents, as moving often means severing ties with friends, schools, and communities (Raviv et al. 1990). An overwhelming body of literature suggests that adolescents who move tend to experience higher levels of psychological duress, perform poorly in school, and display higher levels of problematic behaviors relative to their residentially stable peers (Haynie and South 2005; Metzger et al. 2015). As such, there is a long tradition of social science research aimed at identifying the factors that place some adolescents at a higher risk of moving than others (e.g., South et al. 1998; Gasper et al. 2010; Porter and Vogel 2014). Scholars typically point to the role of family and community factors as 'pushes' that motivate relocation. For instance, changes in family structure or parental employment have been consistently associated with mobility intentions and follow-through (Lee et al. 1994; South and Crowder 1997; Geist and McManus 2008; Vandersmissen et al. 2009; Feijten and van Ham 2013), as have broader indicators of neighborhood quality, such as racial composition, socioeconomic disadvantage, and crime rates (South and Crowder 1997; Xie and McDowall 2008; Hipp and Steenbeek 2015). 
Emerging research suggests that characteristics of sending and receiving neighborhoods may be more consequential than the simple act of moving (Sharkey and Sampson 2010; Vogel et al. 2017). This research has primarily focused on the effects of moving into and out of deprived neighborhoods, as prolonged exposure to socioeconomic disadvantage has been consistently linked to detrimental outcomes in later life (Ellen and Turner 1997; Leventhal and Brooks-Gunn 2000; Clark and Morrison 2012). Generally speaking, this literature demonstrates that families living in impoverished neighborhoods move with greater frequency than those from more affluent areas, and, perhaps not surprisingly, adolescents who are able to leave distressed neighborhoods fare better than those who remain (Crowder and South 2011; Roy et al. 2014). It seems that residential mobility, especially when coupled with downward shifts in neighborhood quality, has profound implications for adolescent development and well-being.

As we elaborate below, two observations complicate prior research in this area. For one, selection bias looms large in both the neighborhood effects and mobility literatures, as there are a number of factors that influence the neighborhoods in which people live as well as their subsequent likelihood of moving out (Sampson 2002; Van Ham and Manley 2012). It remains unclear whether and how neighborhood characteristics influence mobility above and beyond the factors that disproportionately funnel families into particular communities. Second, much of the extant research has treated neighborhoods as islands, examining the effect of residential neighborhood characteristics on subsequent mobility. However, neighborhood processes are rarely spatially independent (Graif et al. 2014) and given the high levels of segregation in many American cities, socioeconomic disadvantage in areas that are nearby residential neighborhoods-oftentimes referred to as extralocal neighborhoods (e.g., Crowder and South 2011)—likely influence the ability of families to relocate. However, limited research has examined the role of spatial dynamics in the relationship between neighborhood deprivation and residential mobility.

The present study builds upon prior research by considering the relationship between neighborhood socioeconomic disadvantage and residential mobility among a representative sample of American adolescents. We move beyond existing scholarship by employing a longitudinal spatial modeling strategy that allows us to assess how (1) changes in socioeconomic disadvantage between sending and receiving neighborhoods and (2) levels of disadvantage in extralocal neighborhoods influence mobility. To our knowledge, this is the first attempt to simultaneously account for selection bias and spatial dynamics in the relationship between neighborhood deprivation and mobility.

\section{Literature Review}

\subsection{Neighborhood Context and Out-Mobility}

A sizeable body of scholarship highlights the importance of individual characteristics and life-course events as factors that stimulate residential mobility. These studies demonstrate that adolescent moves result mainly from circumstances affecting parents, such as changes in family structure (e.g., divorce, remarriage, death) or employment status (e.g., job loss, change, or promotion) (Lee et al. 1994; South et al. 1998; Mulder and Hooimeijer 1999; Feijten and van Ham 2013). Likewise, mobility rates tend to be higher among low-income households (Clark and Morrison 2012), the young (Dieleman 2001), and renters (Kearns and Parkes 2003). Recent research suggests that mobility may also be shaped by neighborhood features that influence families' desire and ability to move. For instance, neighborhood deprivation has been consistently associated with heightened levels of mobility (Clark and Morrison 2012), an effect that might be attributable to lower levels of home-ownership and the relative ease with which many renters can relocate (Kearns and Parkes 2003). Signs of social and physical disorder, such as neighborhood crime rates and the presence of drug dealers, have also been linked with neighborhood out-mobility (Xie and McDowall 2008; Hipp and Steenbeek 2015) suggesting that poor neighborhood conditions reduce residential satisfaction, thereby stimulating out-mobility (Van Ham and Feijten 2008; Rabe and Taylor 2010). 
Changes in neighborhood status-as a result of residential turnover, housing market dynamics, and sociodemographic transitions-may further spur out-mobility. For instance, neighborhood socioeconomic decline is often associated with increased mobility, suggesting that those who can move out do so (Van Ham and Clark 2009). Likewise, increasing ethnic heterogeneity has been shown to stimulate out-mobility among white residents (Van Ham and Feijten 2008; Crowder et al. 2012; Clark and Coulter 2015; Kaufmann and Harris 2015), highlighting the preference of people to live with others from similar racial backgrounds (Sampson and Sharkey 2008; Finney and Simpson 2009; Kaufmann and Harris 2015), an aversion to living near minority neighbors (Krysan 2002), and the perception that minority neighborhoods are prone to crime and socioeconomic deprivation (Quillian and Pager 2001). Taken together, this research indicates that adolescent mobility is not a random process; rather, it reflects some combination of family circumstances, current neighborhood conditions, and socio-demographic backgrounds.

\subsection{Neighborhood Selection and Residential Mobility}

Despite the observed link between neighborhood context and residential mobility, it is unclear whether the relationships uncovered in prior research reflect a true 'neighborhood effect' or if they reflect the higher mobility of families living in deprived and/or declining areas. Indeed, the neighborhood effects literature has been repeatedly criticized for confounding (unobserved) individual characteristics with neighborhood characteristics (e.g., Sampson 2002; Kubrin and Weitzer 2003; Van Ham et al. 2018). Particularly problematic is the fact that many studies fail to control for the non-random selection of residents into particular neighborhoods (Van Ham and Manley 2012) as well as the differential probability that some families will move out (Gasper et al. 2010; Porter and Vogel 2014). From this vantage point, the relationship between neighborhood disadvantage and mobility might be explained by the shared characteristics of residents, such as single parent households, unemployment, or receipt of public welfare, rather than neighborhood features that motivate relocation. As a result, the relationship between neighborhood deprivation and mobility may be coincidentally attributable to a common set of risk factors that both select certain families into specific neighborhoods and increase the likelihood that they will experience a subsequent move (cf. Clark and Morrison 2012).

Experimental research provides some insight into these competing processes. Studies examining the Moving to Opportunity Program (MTO)—a experimental voucher program intended to examine the effects of moving families out of impoverished neighborhoods-suggest that moves into low-poverty neighborhoods are associated with upward social mobility later in life (Rosenbaum et al. 2002; Keels et al. 2005; Sharkey and Sampson 2010; DeLuca and Rosenblatt 2011). These studies also show that families who did not participate in the voucher programs display lower mobility rates over time (Sanbonmatsu et al. 2011), suggesting that neighborhood deprivation may 'trap' families in perpetual cycles of poverty (Jargowsky 1997; Bowles et al. 2006; Sachs 2006). Moreover, many voucher participants ultimately moved back to high-poverty neighborhoods and remained there for extended periods of time, often undoing the advantages of the mobility programs (Orr et al. 2003; Duncan and Zuberi 2006; Comey et al. 2008; Rosenbaum and Zuberi 2010). While the results of these studies are admittedly mixed (Varady 2005; Imbroscio 2008), the quasi-experimental design provides some leverage at addressing threats posed by selection bias. In this sense, we might conclude that neighborhood disadvantage has some effect on residential mobility above and beyond the characteristics of individuals who are most likely to live in deprived neighborhoods, potentially decreasing rather than increasing future mobility.

\subsection{Spatial Dimensions of Community Influences on Mobility}

Even when scholars are able to address selection mechanisms, they often treat neighborhoods as 'islands', ignoring broader community features that may influence mobility intentions and follow-through. For instance, neighborhoods often display a strong degree of spatial dependence, as those with similar socioeconomic and ethnic compositions typically cluster together in space and time 
(Krivo et al. 2013). Community resources, social networks, and transportation patterns often transcend neighborhood boundaries, suggesting that characteristics of extralocal communities may be especially salient factors motivating or inhibiting mobility. However, few studies have considered how spatial processes influence the relationship between neighborhood disadvantage and residential mobility.

This omission is surprising, considering the large differences in mobility patterns across U.S. cities (Long 1988; South and Crowder 1997). Recent studies have found that variation in residential mobility can be partially explained by metropolitan-level characteristics (Crowder et al. 2012). For instance, as short-distance moves are much more common than long distance moves, mobility is often contingent on local housing markets and the availability of attractive and affordable housing in nearby neighborhoods (Crowder and South 2005). Socioeconomic disadvantage in the metropolitan area is likely to produce unattractive conditions (e.g., poor housing stock, high crime rates, low-quality schools), thereby decreasing mobility into and out of these areas (South et al. 2011).

A small body of research has begun to examine how racial dynamics in extralocal areas influences mobility patterns. This research, which is often framed around the phenomenon of 'white flight', suggests that the racial composition of metropolitan areas affects residential mobility by shaping the availability of neighborhoods with various combinations of racial and ethnic groups (Crowder and South 2008; Reibel and Regelson 2011; Crowder et al. 2012). Although ethnic heterogeneity in local neighborhoods tends to spur white mobility, minority concentrations in surrounding areas hinder out-migration, presumably because of the perceived lack of attractive alternatives nearby (Crowder and South 2008). The countervailing effects of extralocal areas are arguably related to different aspects of the mobility decision-making process (Crowder and South 2008) and changes in extralocal areas may provide clues about the future trajectory of a local neighborhood or create a mismatch between neighborhood preferences and actual neighborhood conditions (Taub et al. 1984; Lee et al. 1994; Crowder and South 2008; Feijten and Van Ham 2009).

Building from this work, we might expect the relationships between neighborhood deprivation and mobility to exhibit a similar spatial patterning. Assuming that the ability to move is contingent on the perceived 'quality' of the nearby community, high levels of poverty in extralocal neighborhoods might limit attractive housing alternatives (Crowder et al. 2006), while extralocal affluence may limit the availability of affordable homes. In this sense, holding constant socioeconomic conditions in ones' residential neighborhood, levels of deprivation in geographically proximate neighborhoods may constrain mobility potential by limiting the availability of attractive housing options. Moreover, we might expect levels of extralocal affluence to moderate the association between local neighborhood socioeconomic status and subsequent mobility. For instance, while neighborhood disadvantage may stimulate a desire to move, high levels of affluence in the surrounding area may limit the ability to follow through, as nearby housing options are unattainable. In this sense, extralocal disadvantage might amplify the effect of local neighborhood conditions on out-mobility. Conversely, high levels of disadvantage in geographically proximate neighborhoods may signify a lack of community resources, inadequate schools, and limited labor market opportunities. Under this scenario, high levels of disadvantage in extralocal areas may interact with local levels of disadvantage to reduce the likelihood that families will move out, as nearby options are viewed as equivalent to or worse than their current situation. To borrow a phrase, the spatial concentration of neighborhood disadvantage may act as a 'trap', reducing the likelihood of out-mobility, and ultimately ensnaring families in perpetuating cycles of socioeconomic inequality (Sachs 2006).

\section{Current Study}

While a large body of literature demonstrates a seemingly clear link between neighborhood deprivation and residential mobility, prior work is limited by the threats posed by selection bias and the inability to consider the interactions between broader community features and residential neighborhood characteristics. Thus, it remains unclear whether the oft-observed relationship between neighborhood disadvantage and subsequent mobility reflects a true neighborhood 'effect' or if 
it is attributable to the differential sorting of residentially instable individuals and families into socioeconomically deprived neighborhoods. Moreover, even if the threats posed by endogeneity are negligible, it is unclear how levels of disadvantage in extralocal areas enable or constrain mobility. In this sense, the spatial patterning of neighborhood disadvantage may have profoundly different effects on residential mobility if neighborhoods in the nearby community differ from the neighborhoods in which people currently reside.

Guided by these limitations, the present study builds upon and moves beyond existing scholarship in two key regards. First, we utilize a spatial modeling strategy that allows us to specify unique effects of socioeconomic disadvantage in residential and extralocal neighborhoods. This allows us to (1) compare the effects of local and extralocal neighborhood disadvantage on adolescent mobility and (2) examine the degree to which socioeconomic disadvantage in extralocal areas conditions the effect of local neighborhood disadvantage on out-mobility. Second, we employ a hybrid random effects model that allows us to decompose within and between individual differences in the effect of local and extralocal neighborhood deprivation on residential mobility. Unlike more traditional regression models, this approach allows us to hold constant time-invariant individual differences that might differentially sort certain families into specific neighborhoods.

Our spatial modeling strategy allows us to detect community influences that would otherwise be missed if we considered only residential neighborhood characteristics. The choice of the hybrid regression model allows us to examine not only how neighborhood deprivation influences mobility on the whole, but how changes in neighborhood socioeconomic status between sending and receiving neighborhoods influence subsequent mobility. Departing from prior studies, this empirical framework allows us to address not only selection into neighborhoods, but also selection processes that differentially sort individuals into neighborhoods characterized by varying proximity to other disadvantaged neighborhoods.

\section{Methods}

\subsection{Data}

Data for this analysis are drawn from the first six waves of the National Longitudinal Survey of Youth 1997 (NLSY97). The NLSY97 is a nationally representative sample of American youth who were between the ages of 12 and 16 as of 31 December 1996. The first round of surveys was administered during 1997. Youth respondents have been interviewed on an annual basis since 1997 (with data collection ongoing). As described below, we append tract-level data from the 2000 decennial censuses to the NLSY97 individual records in order to capture the level of socioeconomic disadvantage in the immediate and extralocal neighborhoods in which respondents resided at each of the first six waves of the survey. We limit our analyses to respondents 18 years and younger at each of the survey waves, as the mechanisms driving mobility experiences likely change once individuals graduate high school and transition to higher education and the labor market. Respondents missing on any of the covariates were removed from the analysis via listwise deletion. As discussed below, we also limit our models to respondents who have moved at least once during the observation period (yielding a final sample of 1785 respondents).

\subsection{Measures}

Residential mobility is dichotomous variable differentiating respondents who moved census tracts between each wave of the survey from those who did not. We focus on census tracts for two reasons. First, the census tract is the geographic aggregation that most closely approximates a neighborhood and is used most frequently in studies of neighborhood effects (Sampson 2002). Second, recent studies examining neighborhood effects on youth outcomes in the NLSY97 have consistently relied on tract-level measures of neighborhood characteristics (e.g., Vogel and South 2016; Vogel et al. 2017). 
Our index of neighborhood disadvantage combines the percent of families below the poverty line, the percent of households receiving public assistance, the percent of households headed by women, the percent of the population that is unemployed, and the percent of the population over the age of 25 lacking a high school diploma. These variables are highly intercorrelated and all load on a single factor $($ alpha $=0.924)$. We combine the variables into a single index such that higher scores indicate higher levels of neighborhood disadvantage. We use census data from the year 2000 to generate our measures of disadvantage. Our rationale here is twofold. First, the 2000 census was conducted at the midpoint of our observation period, serving as the least biased, consistent measure of tract disadvantage across waves. Second, using a single point-in-time measure of neighborhood disadvantage, rather than an interpolated value from multiple censuses, allows us to isolate the effect of sending and receiving neighborhood characteristics on subsequent mobility (the main purpose of the analyses) rather than inadvertently measuring the effect of small-scale neighborhood change on mobility. As neighborhood status is rather stable over time (Zwiers et al. 2016), significant changes in neighborhood disadvantage during our observation period are unlikely.

Extralocal neighborhood disadvantage is measured as a spatially lagged, distance-weighted index capturing the level of socioeconomic disadvantage in all census tracts within 100 miles of each respondent's tract of residence. We employ an inverse distance decay function that assigns more weight to levels of disadvantage in geographically proximate neighborhoods and less weight to those that are further away. We then apply the spatial weights generated from this matrix to the index of neighborhood socioeconomic disadvantage described above to generate a measure of extralocal neighborhood disadvantage.

The regression models control for a number of variables that might be associated with both neighborhood disadvantage and residential mobility. Age reflects the age of respondents at the Wave 1 interview. Race differentiates respondents who self-identified as non-Hispanic black, non-Hispanic white, Hispanic, and non-Hispanic other race. Gender is coded 1 for males and 0 for females. The empirical models also control for whether the respondent resided in an urban area (relative to a suburban or rural area).

The models also include several variables intended to control for family background. Measures of family socioeconomic status (SES) include: home ownership, receipt of public assistance, and parent's educational status. Home ownership differentiates homeowners from respondents whose parents rent or lease. Receipt of public assistance is measured as a dichotomous variable indicating whether any member of the respondent's family received food stamps, supplemental security income, or aid to families with dependent children in the 12 months prior to the Wave 1 interview. Family structure differentiates respondents who lived with both biological parents from other living arrangements (single-parent households, step-families, and other family arrangements). The models also control for a lagged measure of mobility, differentiating respondents who moved at the previous wave from those who had not.

\subsection{Analytic Strategy}

We utilize hybrid random effects logistic regression models to analyze the associations between local and extralocal disadvantage on residential mobility. The models take on the form:

$$
\log \left(\frac{y_{i t}}{1+y_{i t}}\right)=\alpha_{i}+\gamma Z_{i}+\beta_{1} L_{i t}+\beta_{2} E_{i t}+\beta_{3} M_{i t-1}+u_{i t}
$$

where $\alpha$ is the regression constant, $Z_{i}$ is the time invariant covariates, $L D_{i t}$ refers to the level of local neighborhood disadvantage for respondent $i$ at time, $t, E D_{i t}$ refers to the level of extralocal disadvantage, and $\mathrm{M}_{\mathrm{it}-1}$ refers to the one-year lag of prior residential mobility. The error term, $\mathrm{u}_{\mathrm{it}}$, can be decomposed into two components:

$$
u_{i t}=\tau_{i}+\varepsilon_{i t}
$$


The first component, $\tau_{i}$, captures individual, time-stable characteristics. The random error term, $\varepsilon_{i t}$, is assumed to be uncorrelated with any of the predictor variables in the equation. This assumption is often untenable as the threat of endogeneity of unmeasured, time-stable covariates looms large. The hybrid model decomposes the time-varying effects into two parts: one reflecting between-person differences and one reflecting within-person differences. The between-person component is calculated as the average of each covariate for individuals over time (e.g., the average level of disadvantage in a respondent's residential census tract for the first six years of the NLSY97). The within-person component is computed as the difference between respondents' scores each wave from their group mean. This is denoted formally as:

$$
\Delta X_{i t}=X_{i t}-\bar{X}_{i t}
$$

These components are included in the hybrid regression such that:

$$
\log \left(\frac{y_{i t}}{1+y_{i t}}\right)=\alpha_{i}+\gamma Z_{i}+\beta_{b 1} \overline{L D}_{i}+\beta_{\mathrm{w} 1} \Delta \mathrm{LD}_{\mathrm{it}}+\beta_{\mathrm{b} 2} \overline{\mathrm{ED}}_{\mathrm{i}}+\beta_{\mathrm{b} 2} \Delta \mathrm{ED}_{\mathrm{it}}+\beta_{\mathrm{b} 4} \mathrm{M}_{\mathrm{it}-1}+\mathrm{u}_{\mathrm{it}} .
$$

The hybrid model has several advantages over traditional modeling strategies for panel data. For one, it provides estimates of both between and within-person effects. Second, the 'fixed' portion of the analysis holds constant any time-invariant variables, thereby reducing the risk of selection bias. Third, the decomposition reduces the potential for the within-individual estimates to be correlated with the time-stable error term, $\tau_{\mathrm{i}}$. Thus, the random coefficients in the model reflect the between-person differences in local and extralocal disadvantage on the likelihood of outward mobility, while the within-person estimates mirror those from a fixed-effects regression, allowing us to assess whether changes in local and extralocal neighborhood disadvantage associated with intertract mobility influence the subsequent probability of out-mobility within individuals over time.

The NLSY97 includes a number of respondents from the same family. Approximately 25 percent of respondents in the analytic sample are from families in which at least one other sibling also participated in the survey. As such, all models are presented with robust standard errors to account for the disproportionate clustering of respondents within families.

\section{Results}

\subsection{Descriptive Statistics}

Table A1 (Appendix A) presents the descriptive statistics for the time-invariant sociodemographic measures included in the analyses. The average age of respondents at Wave 1 was 14.35 years. The majority of respondents are male (52 percent). Forty-nine percent of respondents identify as non-Hispanic white, 26 percent identify as non-Hispanic black, and 21 percent identify as Hispanic. The average household consists of 4.54 members, with 49 percent of respondents reporting living with biological parents, 13 percent in step-families, 32 percent in single parent households, and the remaining 6 percent living in some other family arrangement. For both single parent families and step-families, respondents are more likely to reside with their biological mother than their biological father. The majority of respondents are classified as living in urban areas (73 percent), 53 percent of respondents live in homes owned by their parents, and 22 percent of respondents live in families that received some form of welfare in the past 12 months. Table A2 presents the overall and panel-specific descriptive statistics for mobility status and tract disadvantage. On average, 22 percent of respondents experienced a residential move in any given wave, with panel-specific proportions of movers ranging from 19 percent of the sample to 26 percent of the sample. Trends indicate that levels of disadvantage reduced somewhat over time, perhaps indicating that respondents in the most disadvantaged areas were most likely to attrite from the sample; however, the degree of change in neighborhood quality is negligible. 


\subsection{Multivariate Models}

Table A3 presents the results from the hybrid random effects models. The first model establishes the baseline effect of the sociodemographic controls, lagged mobility, and local neighborhood disadvantage on subsequent mobility. The second model incorporates the lagged measure of extralocal disadvantage. The third model incorporates the product term of local $\mathrm{X}$ extralocal disadvantage. The fourth model incorporates the fixed effects capturing the relative effect of changes in local and extralocal local disadvantage on future mobility within respondents over time. Log odds, odds ratios, and standard errors are presented in the columns. The odds ratios in the random effects models can be interpreted as the expected change in the odds of experiencing a residential move given a one-unit increase in the predictor variable. In the fixed effects model, these coefficients can be interpreted as the expected change in the odds of subsequent mobility for a one standard deviation increase the measure of neighborhood disadvantage within individuals over time.

The findings presented in Model 1 demonstrate that age, Hispanicity, residing in urban areas, and living in non-traditional family arrangements are all positively associated with the likelihood of experiencing residential mobility. For instance, each one-year increase in respondents' age is associated with a 23 percent increase in the odds of mobility. The odds of moving are 12 percent higher among Hispanics than non-Hispanic whites and 11 percent higher among urban dwellers relative to those residing in rural areas. Relative to respondents living with both biological parents, the odds of moving are 41 percent higher among those living with step parents, 24 percent higher among those living in single parent homes, and 36 percent higher among those living in other family arrangements, suggesting that household instability is associated with a higher odds of moving. Family receipt of welfare is associated with a 25 percent reduction in the odds of moving, an effect that may be attributed to benefits that help cover rent. Perhaps not surprisingly, the odds of moving are 14 percent lower among respondents who live in homes owned by their parents (relative to respondents residing in rental units). The coefficient for the lagged measure of mobility suggests that the odds of moving are over three times higher among respondents who reported a residential move at an earlier wave. It seems that respondents who have a history of changing residents have a greater risk of relocating again in the future, while those from residentially stable homes are insulated from experiencing residential mobility.

Model 2 introduces the indicator of local neighborhood disadvantage to the baseline model. The parameter estimate is both statistically significant and positive: a one standard deviation increase in the index of socioeconomic disadvantage is associated with a 5 percent increase in the odds of mobility. This finding is consistent with prior research, and further underscores the higher levels of mobility among families living in disadvantaged areas. Model 3 incorporates the spatially lagged measure of economic deprivation in geographically proximate neighborhoods. The parameter estimate does not reach statistical significance, indicating that socioeconomic disadvantage in the surrounding community provides no additional influence on the likelihood of mobility beyond what is captured by local levels of disadvantage. Model 4 presents the product term between local and extralocal disadvantage. The coefficient is statistically significant and positive, indicating that economic deprivation in geographically proximate neighborhoods exacerbates the effect of local economic disadvantage on the likelihood of moving. In this sense, it seems that families living in areas characterized by concentrated poverty are especially likely to move relative to those living in more affluent areas as well as well those living in pockets of disadvantage.

Model 5 presents the parameter estimates from the within-individual analysis. This model demonstrates that individuals who experience increased neighborhood disadvantage between sending and receiving neighborhoods are significantly less likely to experience a subsequent move. In this case, a one standard deviation increase in neighborhood disadvantage is associated with a 4 percent reduction in the odds of outward mobility. This effect is further compounded among individuals who move to areas surrounded by higher levels of concentrated disadvantage relative to where they began (regardless of the quality of their own neighborhood), as a one standard deviation increase in 
extralocal disadvantage is associated with a 9 percent reduction in the predicted odds of out-mobility. Finally, socioeconomic deprivation in the surrounding community further depresses the likelihood of outward mobility in subsequent waves (as evidenced in the parameter estimate for the product term). This suggests that individuals who move to areas (both local and extralocal neighborhoods) characterized by greater degrees of disadvantage relative to where they begin have the lowest odds of experiencing subsequent mobility.

\section{Discussion}

Residential mobility is considered to be a tumultuous event in the lives of children and adolescents. Emerging research suggests that (1) neighborhood disadvantage increases the likelihood of experiencing a residential move above and beyond individual and family risk factors and (2) decreases in neighborhood quality between sending and receiving neighborhoods may be especially harmful for later life outcomes. Conspicuously absent from this literature is a discussion of the processes that funnel families into particular neighborhoods and an understanding of how levels of socioeconomic disadvantage in the broader community contribute to out-mobility. Accordingly, this study attended to this gap in the literature by applying a longitudinal spatial modeling strategy to address both selection bias and spatial dynamics in the relationship between neighborhood disadvantage and residential mobility among a representative sample of American adolescents.

The results from the random effects models indicate that local neighborhood deprivation is positively associated with residential mobility, further highlighting the elevated levels of mobility among adolescents from economically disadvantaged neighborhoods often observed in prior research. Moving beyond the prior literature, the inclusion of the spatially lagged measure of extralocal disadvantage indicates that levels of socioeconomic disadvantage in nearby neighborhoods magnify the effect of local disadvantage on outmigration. In this sense, the strongest effects of neighborhood deprivation are found among adolescents who reside in areas of concentrated poverty. This suggests that families who live in economically deprived communities are more likely to move when the surrounding community resembles their own neighborhood, potentially pointing to affordable houses nearby, and are less likely to move when the surrounding area is more affluent than their own, perhaps underscoring the limited availability of alternative housing options. Of note, the inclusion of the product term for local $X$ extralocal disadvantage strengthened the parameter estimates for family structure and black and Hispanic race-ethnicity. This may be attributable to the increasing representation of minorities and single and step-families in areas of greater concentrated disadvantage. Collectively, this spatial modeling strategy allows us to capture community influences that are often overlooked, either implicitly or explicitly, in prior research.

The 'fixed' component of the models allows us to assess how changes in neighborhood disadvantage between sending and receiving neighborhoods influence subsequent mobility. This approach addresses selection bias by holding constant time-invariant factors that may differ between respondents living in neighborhoods with varying degrees of disadvantage, thus providing a less-biased estimate of the effect of neighborhood disadvantage on mobility. Departing significantly from prior research as well as the estimates presented in the random effects models, our findings reveal that increases in socioeconomic disadvantage between sending and receiving neighborhoods are negatively associated with future mobility. We speculate that two complementary processes may be at play here. One the one hand, declines in neighborhood quality associated with residential moves may act as 'traps,' decreasing the likelihood that an individual will experience a subsequent move. However, the coefficient also seems to indicate that families who are able to 'move up' are unlikely to hold onto their improved neighborhood statuses, and thus face a greater likelihood of moving in the future. The parameter estimates for the spatially lagged indicator of extralocal disadvantage indicate that the negative effect of neighborhood deprivation is most pronounced among respondents who move to neighborhoods surrounded by other, poorer neighborhoods, suggesting that the mobility-hampering 
effect of neighborhood deprivation is strongest among respondents who move to areas characterized by the highest levels of concentrated poverty, both locally and extralocally.

This finding is especially striking when considered alongside the wealth of literature on the deleterious influences of neighborhood disadvantage on adolescent health and well-being (e.g., Leventhal and Brooks-Gunn 2000). The results presented here suggest that, ceteris paribus, families who move to areas more disadvantaged than where they began are less likely to escape. Similarly, families who experience upward mobility are unlikely to maintain their improved residential status for long, potentially slipping back into economically deprived neighborhoods within a relatively short period of time. Adolescents who become ensnared in such spatial poverty traps may have prolonged exposure to myriad community risk factors, increasing their likelihood of engaging in high-risk behaviors (Sampson et al. 1997) and diminishing their likelihood of graduating high school (Crowder and South 2011), attending college (Garner and Raudenbush 1991), and securing gainful employment in later life (Bauer et al. 2011). From this vantage point, downward mobility and the spatial dynamics of neighborhood disadvantage may be especially salient factors in the perpetuation of socioeconomic inequality among American youth.

We would be remiss not to acknowledge several caveats that potentially undermine the findings reported here. First, as with most studies of neighborhood effects, we rely on administrative designations to capture neighborhood boundaries. The census tract is the most widely used approximation of residential neighborhoods in American scholarship (see Sampson 2002) and is consistent with prior studies linking residential area characteristics to the individual survey responses of NLSY participants (Vogel and South 2016). Of course, administrative boundaries do not perfectly map on to resident perceptions of their "neighborhood" (e.g., Basta et al. 2010) and the level at which neighborhood characteristics are measured can have non-trivial consequences for the observed association between neighborhood features and the outcomes of interest (e.g., Hipp 2007; Petrovic et al. 2018; Vogel 2016). Second, data collection for the NLSY 97 began approximately 20 years ago. A lot has changed in the United States in the intervening years. To our knowledge, these data still reflect one of the most comprehensive and representative longitudinal samples of American adolescents and one of the few national data surveys for which detailed address data are available. Third, while our modeling strategy removes much of the threat posed by omitted time-invariant covariates, the parameter estimates are sensitive to the omission of factors that might vary within respondents over time. In this sense, the models might miss some of the more proximate mechanisms that explain why some families move to affluent areas and others to disadvantaged areas. However, the combination of the fixed-effects regression and the lagged indicator of mobility provide a rather strong correction for endogeneity, further underscoring the robustness of the results presented here. Finally, as our analysis examines adolescent mobility patterns over a relatively short period of time (a maximum of five years per respondent), we can say little about how the spatial dimensions of neighborhood deprivation contribute to mobility over the life course.

We caution readers to interpret our findings with these caveats in mind. Rather than critical limitations, we view these as fruitful avenues for future research. Beyond the purview of the current study, it would be instructive to see whether the findings reported here are sensitive to variation in the aggregation of neighborhood boundaries; for instance, whether the spatial patterning of neighborhood effects holds when measures of socioeconomic disadvantage are aggregated to smaller (or larger) spatial scales. Similarly, given the dated nature of the NLSY97 and the relatively short follow-up, it is important to determine whether these findings can be replicated among more recent samples of American adolescents and whether the observed patterns hold over longer follow-up periods.

Limitations aside, this study expands on scholarship on neighborhood deprivation and residential mobility in several key regards. To our knowledge, this is the first attempt to jointly address the role of selection bias and spatial dynamics in the neighborhood deprivation-mobility relationship. The results from the spatial component of our analyses suggest that researchers interested in neighborhood effects on the behavior of residents need to consider not only the characteristics of immediate 
neighborhood environments, but also characteristics of geographically proximate neighborhoods. As demonstrated here, failure to consider such spatial processes may generate misleading conclusions about the nature of the relationship between neighborhood socioeconomic disadvantage and the mobility patterns of persons living in such areas. As most studies fail to control for residential selection, neighborhood disadvantage may be incorrectly associated with heightened mobility. Once holding constant unobserved time-invariant factors that sort certain families into specific neighborhoods, we find that neighborhood disadvantage actually decreases the odds of subsequent mobility, providing a stronger indication of a 'true' contextual effect. To this end, we strongly encourage future researchers to consider the role of selection bias and spatial dynamics when examining the relationships between neighborhood characteristics and the behavior of residents.

Author Contributions: Conceptualization, M.V. and M.Z.; Formal analysis, M.V.; Funding acquisition, M.V.; Investigation, M.V.; Methodology, M.V. and M.Z.; Writing-original draft, M.V. and M.Z.; Writing—review \& editing, M.V. and M.Z.

Funding: This research received no external funding.

Conflicts of Interest: The authors declare no conflict of interest.

\section{Appendix A}

Table A1. Descriptive Statistics for Individual Characteristics $(\mathrm{N}=1785)$.

\begin{tabular}{ccccc}
\hline & Mean/Prop & SD & Min & Max \\
\hline Age & 14.35 & 1.45 & 12 & 18 \\
Male & 0.52 & - & 0 & 1 \\
Non-Hispanic White & 0.49 & - & 0 & 1 \\
Non-Hispanic Black & 0.26 & - & 0 & 1 \\
Non-Hispanic Other Race & 0.04 & - & 0 & 1 \\
Hispanic & 0.21 & - & 0 & 1 \\
Household Size & 4.54 & 1.54 & 0 & 16 \\
Two Parent Family & 0.49 & - & 0 & 1 \\
Step Family & 0.13 & - & 0 & 1 \\
Single Parent & 0.32 & - & 0 & 1 \\
Other Family Structure & 0.06 & - & 0 & 1 \\
Receipt of Welfare & 0.22 & - & 0 & 1 \\
Parental Home Owner & 0.53 & - & 0 & 1 \\
Urban & 0.73 & - & 0 & 1 \\
\hline
\end{tabular}

Abbreviations: SD = standard deviation; Notes: All variables measured at time of Wave 1 interview. Source: National Longitudinal Survey of Youth, 1997.

Table A2. Wave-Specific Measures of Neighborhood Disadvantage and Mobility Status.

\begin{tabular}{ccccccccccc}
\hline & W1 & W2 & W3 & W4 & W5 & W6 & $\begin{array}{c}\text { Overall } \\
\text { Mean }\end{array}$ & $\begin{array}{c}\text { Overall } \\
\text { SD }\end{array}$ & $\begin{array}{c}\text { Between } \\
\text { SD }\end{array}$ & $\begin{array}{c}\text { Within } \\
\text { SD }\end{array}$ \\
\hline $\begin{array}{c}\text { Mover Status } \\
\text { (Y/N) }\end{array}$ & - & 0.22 & 0.19 & 0.22 & 0.26 & 0.25 & 0.22 & 0.42 & 0.21 & 0.31 \\
$\begin{array}{c}\text { Neighborhood } \\
\text { Disadvantage }\end{array}$ & 0.38 & 0.35 & 0.28 & 0.26 & 0.24 & 0.23 & 0.31 & 1.98 & 1.87 & 0.68 \\
\hline
\end{tabular}


Table A3. Hybrid Random Effects Logistic Regression Estimates of Neighborhood Disadvantage, Extralocal Disadvantage, and Demographic Controls on Likelihood of Inter-tract Mobility ( $\mathrm{N}=1785)$.

\begin{tabular}{|c|c|c|c|c|c|c|c|c|c|c|c|c|c|c|c|c|}
\hline & \multicolumn{12}{|c|}{ Between-Group (Random) Effects } & \multirow{2}{*}{\multicolumn{4}{|c|}{$\begin{array}{c}\text { Within-Group (Fixed) Effects } \\
\text { Model } 4\end{array}$}} \\
\hline & \multicolumn{4}{|c|}{ Model 1} & \multicolumn{4}{|c|}{ Model 2} & \multicolumn{4}{|c|}{ Model 3} & & & & \\
\hline & B & OR & se & & B & OR & se & & B & OR & se & & B & OR & se & \\
\hline Intercept & -3.53 & & 0.18 & $* * *$ & -3.51 & & 0.18 & $* * *$ & -3.11 & & 0.17 & $* * *$ & - & - & - & \\
\hline Age & 0.21 & 1.23 & 0.02 & $* * *$ & 0.21 & 1.23 & 0.02 & $* * *$ & 0.16 & 1.17 & 0.01 & $* * *$ & - & - & - & \\
\hline Male & -0.07 & 0.93 & 0.03 & $* * *$ & -0.07 & 0.93 & 0.03 & $* * *$ & -0.12 & 0.89 & 0.03 & $* * *$ & - & - & - & \\
\hline Non-Hispanic Black & 0.06 & 1.06 & 0.06 & & 0.06 & 1.06 & 0.06 & & 0.08 & 1.08 & 0.06 & * & - & - & - & \\
\hline Non-Hispanic Other Race & 0.08 & 1.08 & 0.09 & & 0.08 & 1.08 & 0.09 & & 0.08 & 1.08 & 0.09 & & - & - & - & \\
\hline Hispanic & 0.11 & 1.12 & 0.05 & $* *$ & 0.11 & 1.12 & 0.05 & $* *$ & 0.16 & & 0.05 & $* *$ & - & - & - & \\
\hline Household Size & -0.17 & 0.84 & 0.01 & $* * *$ & -0.17 & 0.84 & 0.01 & $* * *$ & -0.25 & & 0.01 & $* * *$ & - & - & - & \\
\hline Step Family & 0.35 & 1.41 & 0.05 & $* * *$ & 0.39 & 1.41 & 0.05 & $* * *$ & 0.39 & 1.47 & 0.03 & $* * *$ & - & - & - & \\
\hline Single Parent & 0.21 & 1.24 & 0.07 & $* * *$ & 0.24 & 1.24 & 0.07 & $* * *$ & 0.24 & 1.27 & 0.06 & $* * *$ & - & - & - & \\
\hline Other Family Structure & 0.31 & 1.36 & 0.09 & $* * *$ & 0.36 & 1.36 & 0.09 & $* * *$ & 0.36 & 1.43 & 0.08 & $* * *$ & - & - & - & \\
\hline Receipt of Welfare & -0.29 & 0.75 & 0.08 & $* * *$ & -0.29 & 0.75 & 0.08 & $* * *$ & -0.29 & 0.75 & 0.08 & $* * *$ & - & - & - & \\
\hline Parental Home Owner & -0.15 & 0.86 & 0.06 & $* *$ & -0.15 & 0.86 & 0.05 & $* *$ & -0.15 & 0.86 & 0.06 & $* *$ & - & - & - & \\
\hline $\operatorname{Urban}(=1)$ & 0.10 & 1.11 & 0.04 & $*$ & 0.10 & 1.11 & 0.03 & * & 0.08 & 1.08 & 0.04 & * & - & - & - & \\
\hline Neighborhood Disadvantage & 0.05 & 1.05 & 0.02 & $* * *$ & 0.05 & 1.05 & 0.02 & $* * *$ & 0.13 & 1.14 & 0.02 & $* * *$ & -0.04 & 0.96 & 0.02 & * \\
\hline Extralocal Disadvantage & - & - & - & & 0.01 & 1.01 & 0.02 & & 0.01 & 1.01 & 0.03 & & -0.09 & 0.91 & 0.03 & ** \\
\hline Local X Extralocal Disadvantage & - & - & - & & - & - & - & & 0.03 & 1.02 & 0.01 & $* *$ & -0.03 & 0.97 & 0.01 & $* * *$ \\
\hline Lagged Mobility & 1.27 & 3.56 & 0.06 & $* * *$ & 1.27 & 3.56 & 0.06 & $* * *$ & 1.29 & 3.60 & 0.06 & $* * *$ & - & - & - & \\
\hline
\end{tabular}

Abbreviations: OR = odds ratio; se $=$ standard error; ${ }^{*} p<0.05 ;{ }^{* *} p<0.01 ;{ }^{* * *} p<0.001$. Source: National Longitudinal Survey of Youth, $1997 ; 2000$ Decennial Census. 


\section{References}

Basta, Luke A., Therese S. Richmond, and Douglas J. Wiebe. 2010. Neighborhoods, daily activities, and measuring health risks experienced in urban environments. Social Science $\mathcal{E}$ Medicine 71: 1943-50.

Bauer, Jean W., Patricia H. Dyk, Seohee Son, and Elizabeth M. Dolan. 2011. Rural does matter: Understanding the rural context. In Rural Families and Work. Edited by J. W. Bauer and E. M. Dolan. New York: Springer, pp. 37-54.

Bowles, Samual, Steven N. Durlauf, and Karla Hoff. 2006. Poverty Traps. Princeton: Princeton University Press.

Clark, William A.V., and Rory Coulter. 2015. Who wants to move? The role of neighbourhood change. Environment and Planning A 47: 2683-709. [CrossRef]

Clark, William A.V., and Phillip S. Morrison. 2012. Socio-spatial mobility and residential sorting: Evidence from a large-scale survey. Urban Studies 49: 3253-70. [CrossRef]

Comey, Jennifer, Xavier de Souza Briggs, and Gretchen Weismann. 2008. Struggling to Stay Out of High-Poverty Neighborhoods: Lessons from the Moving to Opportunity Experiment. Washington, DC: The Urban Institute.

Crowder, Kyle, and Scott J. South. 2005. Race, class, and changing patterns of migration between poor and nonpoor neighborhoods. American Journal of Sociology 110: 1715-63. [CrossRef]

Crowder, Kyle, and Scott J. South. 2008. Spatial dynamics of white flight: The effects of local and extralocal racial conditions on neighborhood out-migration. American Sociological Review 73: 792-812. [CrossRef] [PubMed]

Crowder, Kyle, and Scott J. South. 2011. Spatial and temporal dimensions of neighborhood effects on high school graduation. Social Science Research 40: 87-106. [CrossRef] [PubMed]

Crowder, Kyle, Scott J. South, and Erick Chavez. 2006. Wealth, race, and inter-neighborhood migration. American Sociological Review 71: 72-94. [CrossRef]

Crowder, Kyle, Jeremy Pais, and Scott J. South. 2012. Neighborhood diversity, metropolitan constraints, and household migration. American Sociological Review 77: 325-53. [CrossRef] [PubMed]

DeLuca, Stefanie, and Peter Rosenblatt. 2011. Increasing Access to High Performing Schools in an Assisted Housing Voucher Program. Report prepared for the Department of Housing and Urban Development and the Department of Education, Research and Policy Roundtable: Coordinating Housing and Education Policy to Support Racial and Economic Integration. Available online: http://www.prrac.org/pdf/ HousingEducationReport-October2011.pdf (accessed on 15 September 2018).

Dieleman, Frans M. 2001. Modelling residential mobility; a review of recent trends in research. Journal of Housing and the Built Environment 16: 249-65. [CrossRef]

Duncan, Greg J., and Anita Zuberi. 2006. Mobility lessons from Gautreaux and moving to opportunity. Northwestern Journal of Law and Social Policy 1: 110-26.

Ellen, Ingrid Gould, and Mary Austin Turner. 1997. Does neighborhood matter? Assessing recent evidence. Housing Policy Debate 8: 833-66. [CrossRef]

Feijten, Peteke, and Maarten Van Ham. 2009. Neighbourhood change ... reason to leave? Urban Studies 46: 2103-22. [CrossRef]

Feijten, Peteke, and Maarten van Ham. 2013. The consequences of divorce and splitting up for spatial mobility in the UK. Comparative Population Studies 38: 405-32.

Finney, Nissa, and Ludi Simpson. 2009. 'Sleepwalking to Segregation'? Challenging Myths about Race and Migration. Bristol: Policy Press.

Gasper, Joseph, Stefanie DeLuca, and Angela Estacion. 2010. Coming and going: Explaining the effects of residential and school mobility on adolescent delinquency. Social Science Research 39: 459-76. [CrossRef]

Garner, Catherine L., and Stephen W. Raudenbush. 1991. Neighborhood effects on educational attainment: A multilevel analysis. Sociology of education 64: 251-262. [CrossRef]

Geist, Claudia, and Patricia A. McManus. 2008. Geographical mobility over the life course: Motivations and implications. Population, Space and Place 14: 283-303. [CrossRef]

Graif, Corina, Andrew S. Gladfelter, and Stephen A. Matthews. 2014. Urban poverty and neighborhood effects on crime: Incorporating spatial and network perspectives. Sociology Compass 8: 1140-55. [CrossRef] [PubMed]

Haynie, Dana L., and Scott J. South. 2005. Residential mobility and adolescent violence. Social Forces 84: 361-74. [CrossRef]

Hipp, John R. 2007. Block, tract, and levels of aggregation: Neighborhood structure and crime and disorder as a case in point. American Sociological Review 72: 659-80. [CrossRef] 
Hipp, John R., and Wouter Steenbeek. 2015. Types of crime and types of mechanisms what are the consequences for neighborhoods over time? Crime and Delinquency 62: 1203-34. [CrossRef]

Imbroscio, David. 2008. United and actuated by some common impulse of passion: Challenging the dispersal consensus in American housing policy research. Journal of Urban Affairs 30: 111-30. [CrossRef]

Jargowsky, Paul A. 1997. Poverty and Place: Ghettos, Barrios, and the American City. New York: Russell Sage Foundation.

Kaufmann, Eric, and Gareth Harris. 2015. "White Flight” or positive contact? Local diversity and attitudes to immigration in Britain. Comparative Political Studies 48: 1563-90. [CrossRef]

Kearns, Ade, and Alison Parkes. 2003. Living in and leaving poor neighbourhood conditions in England. Housing Studies 18: 827-51. [CrossRef]

Keels, Micere, Greg J. Duncan, Stefanie DeLuca, Ruby Mendenhall, and James Rosenbaum. 2005. Fifteen years later: Can residential mobility programs provide a long-term escape from neighborhood segregation, crime and poverty? Demography 42: 51-73. [CrossRef] [PubMed]

Krivo, Lauren J., Heather M. Washington, Ruth D. Peterson, Christopher R. Browning, Catherine A. Calder, and Mei-Po Kwan. 2013. Social isolation of disadvantage and advantage: The reproduction of inequality in urban space. Social Forces 92: 141-64.

Krysan, Maria. 2002. Whites who say they'd flee: Who are they, and why would they leave? Demography 39: 675-96. [CrossRef] [PubMed]

Kubrin, Charis E., and Ronald Weitzer. 2003. New directions in social disorganization theory. Journal of Research in Crime and Delinquency 40: 374-402. [CrossRef]

Lee, Barrett. A., R. S. Oropesa, and James W. Kanan. 1994. Neighborhood context and residential mobility. Demography 31: 249-70. [CrossRef] [PubMed]

Leventhal, Tamara, and Jean Brooks-Gunn. 2000. The neighborhoods they live in: The effects of neighborhood residence on child and adolescent outcomes. Psychological Bulletin 126: 309. [CrossRef] [PubMed]

Long, Larry. 1988. Migration and Residential Mobility in the United States. New York: Russell Sage Foundation.

Metzger, Molly W., Patrick J. Fowler, Courtney L. Anderson, and Constance A. Lindsay. 2015. Residential mobility during adolescence: Do even "upward" moves predict dropout risk? Social Science Research 53: 218-30. [CrossRef] [PubMed]

Mulder, Clara H., and Pieter Hooimeijer. 1999. Residential relocations in the life course. In Population Issues. The Netherlands: Springer, pp. 159-86.

Orr, Larry, Judith D. Feins, Robin Jacob, Erik Beecroft, Lisa Sabonmatsu, Lawrence F. Katz, Jeffrey B. Liebman, and Jeffrey R. Kling. 2003. Moving to Opportunity Interim Impacts Evaluation; Washington, DC: US Department of Housing and Urban Development, Office of Policy Development and Research.

Petrovic, Anna, Maarten van Ham, and David Manley. 2018. Multiscale Measures of Population: Within-and between-City Variation in Exposure to the Sociospatial Context. Annals of the American Association of Geographers, 1-18. [CrossRef]

Porter, Lauren, and Matt Vogel. 2014. Residential mobility and delinquency revisited: Causation or selection? Journal of Quantitative Criminology 30: 187-214.

Quillian, Lincoln, and Devah Pager. 2001. Black Neighbors, Higher Crime? The Role of Racial Stereotypes in Evaluations of Neighborhood Crime. American Journal of Sociology 107: 717-67. [CrossRef]

Rabe, Birgitta, and Mark Taylor. 2010. Residential mobility, quality of neighbourhood and life course events. Journal of the Royal Statistical Society: Series A (Statistics in Society) 173: 531-55. [CrossRef]

Raviv, Amiram, Giora Keinan, Yehuda Abazon, and Raviv Alona. 1990. Moving as a stressful life event for adolescents. Journal of Community Psychology 18: 130-40. [CrossRef]

Reibel, Michael, and Moira Regelson. 2011. Neighborhood racial and ethnic change: The time dimension in segregation. Urban Geography 32: 360-82. [CrossRef]

Rosenbaum, James E., and Anita Zuberi. 2010. Comparing residential mobility programs: Design elements, neighborhood placements, and outcomes in MTO and Gautreaux. Housing Policy Debate 20: 27-41. [CrossRef]

Rosenbaum, James E., Lisa Reynolds, and Stefanie DeLuca. 2002. How do places matter? The geography of opportunity, self-efficacy, and a look inside the black box of residential mobility. Housing Studies 17: 71-82. [CrossRef]

Roy, Amanda L., Dana C. McCoy, and C. Cybele Raver. 2014. Instability versus quality:Residential mobility, neighborhood poverty, and children's self-regulation. Developmental Psychology 50: 1891-96. [CrossRef] [PubMed] 
Sachs, Jeffrey D. 2006. The End of Poverty: Economic Possibilities for Our Time. London: Penguin Press.

Sampson, Robert J. 2002. Transcending tradition: New directions in community research, Chicago style. Criminology 40: 213-30. [CrossRef]

Sampson, Robert J., and Patrick Sharkey. 2008. Neighborhood selection and the social reproduction of concentrated racial inequality. Demography 45: 1-29. [CrossRef] [PubMed]

Sampson, Robert J., Stephen W. Raudenbush, and Felton Earls. 1997. Neighborhoods and violent crime: A multilevel study of collective efficacy. Science 277: 918-24. [CrossRef] [PubMed]

Sanbonmatsu, Lisa, Jens Ludwig, Lawrence F. Katz, Lisa A. Gennetian, Greg J. Duncan, Ronald C. Kessler, Emma Adam, Thomas W. McDade, and Stacey Tessler Lindau. 2011. Moving to Opportunity for Fair Housing Demonstration Program: Final Impacts Evaluation; Washington, DC: U.S. Department of Housing and Urban Development, Office of Policy Development and Research.

Sharkey, Patrick, and Robert J. Sampson. 2010. Destination effects: Residential mobility and trajectories of adolescent violence in a stratified metropolis. Criminology 48: 639-81. [CrossRef] [PubMed]

South, Scott J., and Kyle D. Crowder. 1997. Escaping distressed neighborhoods: Individual, community, and metropolitan influences. American Journal of Sociology 102: 1040-84. [CrossRef]

South, Scott J., Kyle D. Crowder, and Kathy Trent. 1998. Children's residential mobility and neighborhood environment following parental divorce and remarriage. Social Forces 77: 667-93. [CrossRef]

South, Scott J., Kyle D. Crowder, and Jeremy Pais. 2011. Metropolitan structure and neighborhood attainment: Exploring intermetropolitan variation in racial residential segregation. Demography 48: 1263-92. [CrossRef] [PubMed]

Taub, Richard, D. Garth Taylor, and Jan D. Dunham. 1984. Paths of Neighborhood Change: Race and Crime in Urban America. Chicago: Nelson Hall.

Van Ham, Maarten, and William A. Clark. 2009. Neighbourhood mobility in context: household moves and changing neighbourhoods in the Netherlands. Environment and planning A 41, (6): 1442-1459. [CrossRef]

Van Ham, Maarten, and Peteke Feijten. 2008. Who wants to leave the neighbourhood? The effect of being different from the neighbourhood population on wishes to move. Environment and Planning A 40: 1151-70. [CrossRef]

Van Ham, Maarten, and David Manley. 2012. Neighbourhood effects research at a crossroads. Ten challenges for future research. Environment and Planning A 44: 2787-93. [CrossRef]

Van Ham, Maarten, Sanne Boschman, and Matt Vogel. 2018. Incorporating Neighborhood Choice in a Model of Neighborhood Effects on Income. Demography 55: 1069-90. [CrossRef] [PubMed]

Vandersmissen, Marie-Helene, Anne-Marie Séguin, Marius Thériault, and Christophe Claramunt. 2009. Modeling propensity to move after job change using event history analysis and temporal GIS. Journal of Geographical Systems 11: 37-65.

Varady, David P. 2005. Desegregating the City. Albany: SUNY Press.

Vogel, Matt. 2016. The modifiable areal unit problem in person-context research. Journal of Research in Crime and Delinquency 53: 112-35. [CrossRef]

Vogel, Matt, and Scott J. South. 2016. Spatial Dimensions of the Effect of Neighborhood Disadvantage on Delinquency. Criminology 53: 434-58. [CrossRef]

Vogel, Matt, Lauren C. Porter, and Timothy McCuddy. 2017. Hypermobility, destination effects, and delinquency: Specifying the link between residential mobility and offending. Social Forces 95: 1261-84. [CrossRef]

Xie, Min, and David McDowall. 2008. Escaping crime: The effects of direct and indirect victimization on moving. Criminology 46: 809-40. [CrossRef]

Zwiers, Merle, Reinout Kleinhans, and Maarten van Ham. 2016. The path-dependency of low-income neighbourhood trajectories: An approach for analysing neighbourhood change. Applied Spatial Analysis and Policy 10: 363-80. [CrossRef]

(C) 2018 by the authors. Licensee MDPI, Basel, Switzerland. This article is an open access article distributed under the terms and conditions of the Creative Commons Attribution (CC BY) license (http://creativecommons.org/licenses/by/4.0/). 